\title{
Study on morphological changes induced by aspartame on liver of normal and diabetic male albino rats
}

Bothaina M. Khidr, Gamal H. El-Sokkary and Shaimaa M.M. Saleh*

*Correspondence: omjasminejory@yahoo.com

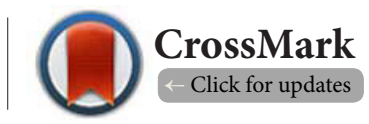

Department of Zoology Faculty of Science Assiut University, Assiut, 71516 Egypt, Egypt.

\begin{abstract}
Background: This work was designed to study the histological and ultrastructure abnormalities in the liver induced by high dose of aspartame (ASP) in normal and diabetic rats.

Methods: Forty adult male rats were used in this study and divided into four groups with ten animals for each. Rats of group one served as controls and administered vehicle. Rats of group two were administered aspartame (ASP) at $200 \mathrm{mg} / \mathrm{Kg}$ bwt once daily for 4 weeks. Rats of group three (D) were given streptozotocin (STZ) one time at a dose of $70 \mathrm{mg} / \mathrm{Kg}$ bwt. The fourth group (D+ASP) was represented by diabetic rats administered with aspartame at $200 \mathrm{mg} / \mathrm{Kg}$ bwt.

Results: The most obvious changes that occurred in the liver treated rats were destruction of hepatocytes which led to necrosis, the appearance of large areas of rarified cytoplasm separating dense areas of cellular organelles, disorganization of cellular organelles, increase in collagenous fibers and depletion of polysaccharides (carbohydrate content of hepatocytes).

Conclusions: Our results indicated that ASP administration may be responsible for the morphological alternations of liver in both normal and diabetic animals.
\end{abstract}

Keywords: Aspartame, diabetes, streptozotocin, ultrastructure

\section{Introduction}

Food additives are substances not normally found in foods but are added to sweeten food to extend their shelf life, and improve flavor, colour and texture. The majority of highly prossed foods cannot be made without them. Antioxidants, preservatives, sweeteners, colorant, flavors, emulsifiers and stabilizers are examples of food additives [1]. Sweeteners could be classified as natural nutritive and artificial non-nutritive. Monosaccharides, disaccharides and sugar alcohols from either natural or refined sources are Nutritive sweeteners. Many nutritive sweeteners are used in food and white sugar, brown sugar, honey, corn syrup, glucose, and fructose and etc... are just some of them [2]. Non nutritive sweeteners are also referred to as intense sweeteners, very low caloric or alternative sweeteners. One of these sweeteners is aspartame (ASP) [3].

ASP is one of the most widely used of sweeteners in the world [4] and was accidentally discovered in 1965 by James M. Schlatter a chemist at G.D. Searle in the US, who was working on a new drug to treat gastric ulcers [5]. It is produced commercially from the methyl ester of two amino acids; L-aspartic and L-phenylalanine [6]. ASP is used frequently nowadays to reduce sugar consumption and to decrease caloric intake in healthy person as well as in diabetic patients [7]. It is slowly making its way into ordinary products used every day [8]. This sweetener ASP possesses 180-200 times the sweetness potency of sucrose and has a caloric value of 4/kcal/g [9].

ASP is used mostly in foods that don't require cooking or baking. It often breaks down when heated and loses much of its sweetness, so it is used in puddings, gelatins, frozen desserts, yogurt, toppings and filling in precooked bakery goods and cookies, instant tea and coffee, breath mints, chewing gum, and as a substitute for granulated sugar [1]. Also it is used in hygiene products, and drugs such as cough therapy [10].

Diabetes is a chronic disease that is relatively common throughout the world. It is a complex metabolic disorder resulting from either insulin insufficiency or insulin deficiency dysfunction [11]. The induction of experimental diabetes in rats is very convenient and simple by using chemicals which selectively destroy pancreatic beta cells ( $\beta$ cells). The substances most usually used for diabetes induction in the rat are alloxan and streptozotocin 
Khidr et al. Journal of Histology \& Histopathology 2017,

http://www.hoajonline.com/journals/pdf/2055-091X-4-1.pdf

doi: 10.7243/2055-091X-4-1

(STZ) [12]. STZ causes a state of insulin-dependent diabetes mellitus via inhibition of insulin secretion. Its effects can be seen after intravenous administration within seventy two hour depending on the dose administered [13]. After administration of STZ to rats, it mostly accumulated in the liver and kidney, and in the pancreas at lower amounts, but mostly combined to pancreatic protein [14].

The liver is a chief metabolic organ responsible for disposal of up to one third of an oral glucose load and involved in the regulation of glucose metabolism [15].

The aim of the current study was to investigate the effect of aspartame administration on the morphological, histochemical and ultrastructural features in the liver of normal and diabetic adult male albino rats.

\section{Material and methods Animals}

Forty adult male Sprague-Dawely albino rats, weighting $225 \pm 5$ $\mathrm{g}$ were used in this work obtained from Assiut University Joint Animal Breeding. All rats kept under the same laboratory conditions (temperature [25 \pm 2 ] lighting [12:12 light dark cycle]) and were given free access of standard food and tap water.

\section{Chemicals}

Streptozotocin was purchased from Sigma (St. Louis, Mo, USA), aspartame pure powder was gift from T3A Company Assiut branch. All other chemical used are in high quality.

\section{Experimental design and procedures}

Rats were divided into four groups, ten rats for each. The first group served as control and was dosed with vehicle only. The second group was administered with aspartame $(200 \mathrm{mg} / \mathrm{kg}$ bwt dissolved in distilled water). Animals of third and fourth groups were given a single dose of STZ (70 mg/kg bwt) in citrate buffer. The third group served as diabetic group while fourth group administered with ASP after 2 days of STZ injection. The experimental period was 4 weeks. At the end of the current experiment, animals were killed and livers were removed and prepared for the different histological examinations. The care and treatment of the animals was approved and performed according to the guidelines of the University of Assiut.

\section{Induction of diabetes}

The fasted animals were given a single intraperitoneal dose of STZ (70 mg/Kg bwt) dissolved in freshly prepared citrate buffer (0.1 M), pH 7.0 [16]. After $48 \mathrm{~h}$ animals were considered diabetic. The rats with fasting diabetes having blood glucose level of $250 \mathrm{mg} / \mathrm{dl}$ or above were considered diabetic. Rats with $400 \mathrm{mg} / \mathrm{dl}$ blood glucose level and above during the experiment treated with $100-200 \mu / l$ of insulin to avoid death.

\section{Histological and histochemical studies}

For light microscopic study, the specimens were fixed in formal alcohol. Blocks were made and paraffin sections were cut 5-7 $\mu \mathrm{m}$ thick, stained with haematoxylin and eosin and Masson's trichrom stain. To investigate the polysaccharide condensation, the sections were stained by Periodic acid Schiff (PAS). All sections were examined using light microscope and photographed. All methods were applied according to Drury and Wallington [17].

\section{Electron microscopy}

For Electron microscopy, small pieces were taken from the livers of all animal groups and fixed in $5 \%$ cold glutaraldehyde for 24 hours. The specimens were then washed in 3-4 changes of cocodylate buffer (PH 7.2) and post fixed in cold osmium tetroxide for $2 \mathrm{hrs}$. Then, the specimens were washed in four changes of cocodylate buffer (20 minutes each). Dehydration was achieved using ascending grades of ethyl alcohol (30\%-50\%-70\%) each for $2 \mathrm{hrs}$ and 90\%, 100\%, 2 changes 30 minutes each, cleared in propylene oxide and embedded in Epon 812 kit using gelatin capsules. The embedded samples were kept in the incubator at $35^{\circ} \mathrm{C}$ for one day, then at $45^{\circ} \mathrm{C}$ for another day and at $60^{\circ} \mathrm{C}$ in the other days for Polymerization [18]. Ultrathin sections $(50-80 \mathrm{~nm})$ from selected areas were collected on copper grids. The Ultrathin sections were contrasted in uranyle acetate for 10 minutes, lead citrate for 5 $\mathrm{min}$. and examined by the transmission electron microscope (Jeol 100X) and photographed.

\section{Results}

In control rats, the normal structure of liver was observed (group 1) as shown in Figures $\mathbf{1 A}$ and $\mathbf{1 B}$. In the present investigation, there was a remarkable change in the liver of the male albino rats in all treated groups. Rats that received ASP (group 2) showed severe histological changes, in the form of disorganized hepatic tissue and necrotic areas. In hepatic lobules, the necrotic areas associated with mononuclear cell infiltration were detected (Figure 1C). Moreover leucocytic aggregations, mostly lymphatic in nature were seen around congested blood vessels and bile ducts in portal areas (Figure 1D). Examination of semithin sections of ASP revealed vacuolation with deeply stained nuclei. The amount of glycogen in some hepatocytes take pink stain and dilated and congested sinusoids (Figure 1F).

Examination of liver sections in diabetic animals (group 3) showed vacuolated hepatocytes with deeply stained nuclei (Figuure 2A). Areas of hepatic necrosis appeared in some regions (Figure 2B). Sometimes, patches of leucocytic aggregation, mostly lymphatic were observed. Examination of semithin sections showed various stages of cytoplasmic degeneration changes in the form of unstained regions devoid from cytoplasmic contents. Some cells exhibit metachromatic staining (Figure 2C). Few of hepatocytes showed homogeneous toluidine blue stained inclusions among unstained cytoplasmic vacuolation. Meanwhile other hepatocytes were hypertrophic due to increase in intracytoplasmic metachromatic granules (Figures 2C and 2D). Moreover the nuclei of binuclear hepatocytes were not identical in staining characteristics and they 


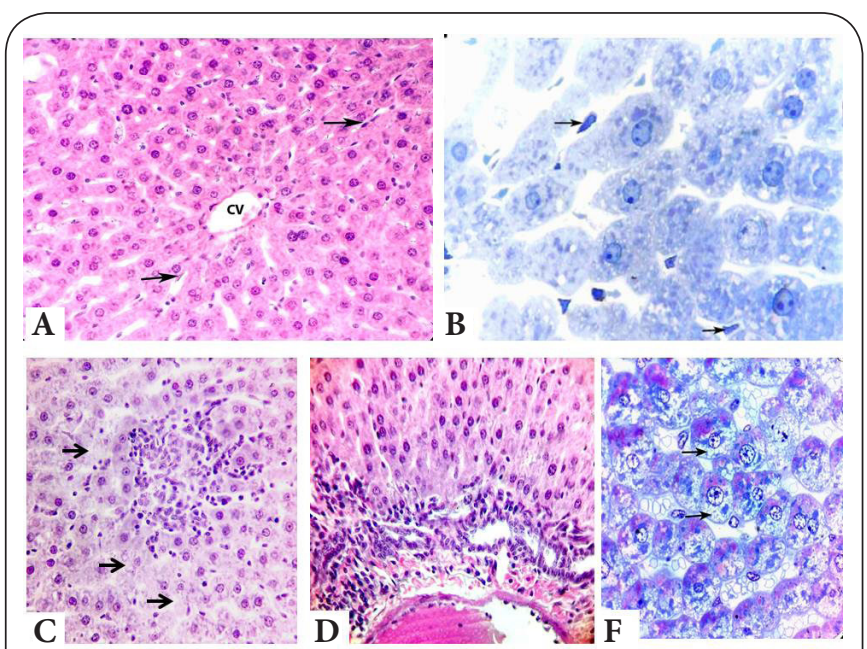

Figure 1. (A). Liver section showing normal polyhedral hepatocytes and their radiation from the central vein $(\mathrm{CV})$ with eosinophilic cytoplasm and centrally located nuclei. Between the cords of hepatocytes, blood sinusoids are often seen with phagocytic Kuffer cells (arrows) (H\&E, X400). (B). Semithin section of normal liver showing hepatocyte and Kupffer cells $(\uparrow)$ (Toluidine blue, X1000). (C). ASP treated liver: Necrotic areas associated with mononuclear cell infiltration (arrows) (H\&E, X400). (D). ASP treated liver showing inflammation in the portal area (H\&E, X400). (E). ASP treated liver showing vacuolation of hepatocytes (arrows), amount of glycogen in some hepatocytes take pink stain and dilated and congested sinusoids (head arrow) (Toluidine blue, X1000).

were varied in size (Figure 2E).

Sections of the livers of group 4 (D+ASP) appear more or less similar to the two previous treated groups, in respect to the presence of large necrotic area, loss of most of the architecture of the liver tissue, loss of cell boundaries, degeneration in most of the hepatocytes and the nuclei of some cells appeared dark stain (Figure 2F).

Masson's trichrom stain of control liver showed small (normal) amount of collagenous fibers surrounded the central veins and portal areas (Figure 3A). In ASP group, there was large amount of collagenous fibers around portal areas compared to the control group (Figure 3B). In diabetic rats (D group), there was focal fibrous area between liver cells (Figure 3C). The group which received D+ASP, an increment in the amount of collagenous fibers around portal areas compared to the control group. The amount of collagenous fibers in this group appears more or less similar to two previous treated groups (Figure 3D).

Histochemically, PAS reaction revealed normal distribution of polysaccharides in the control liver cells as illustrated in (Figure 4A). These figures showed a considerable amount of polysaccharides granules in the ground cytoplasm of hepatocytes. There is a pale rounded area within the cells which represents the site of nuclei.

After administration of ASP, PAS reaction showed large

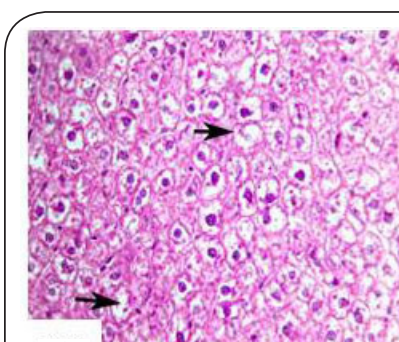

A
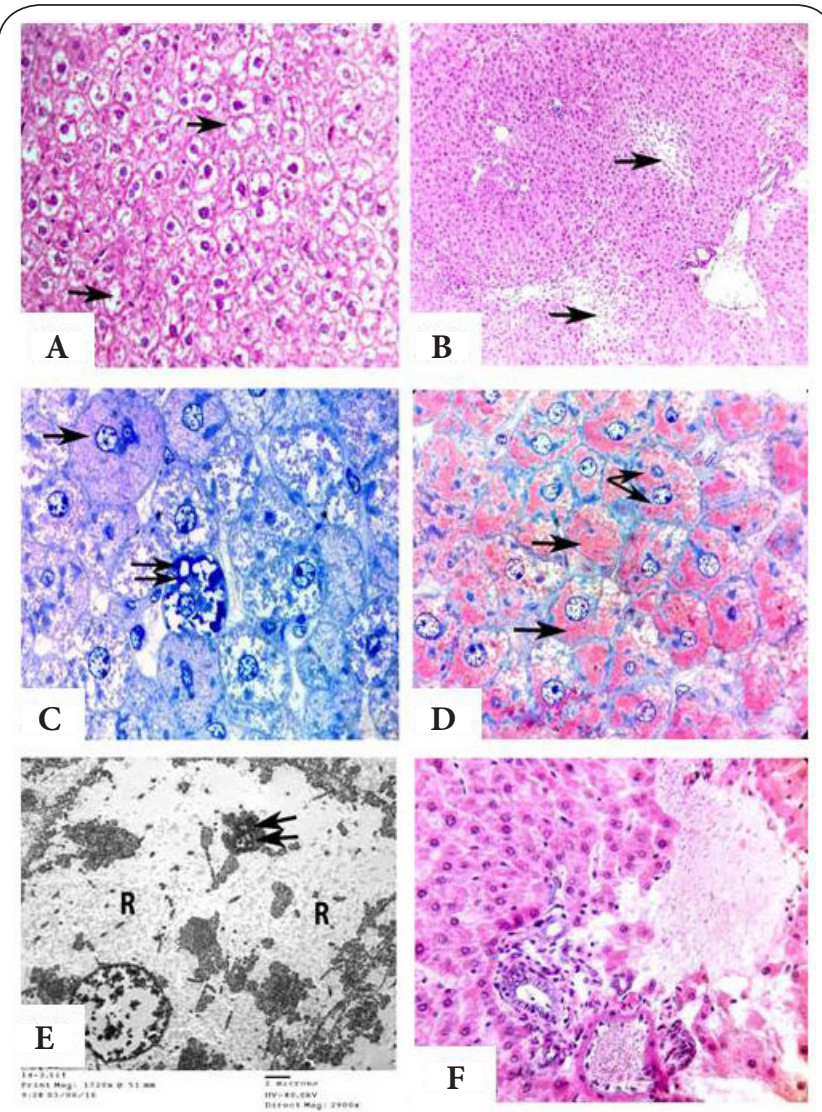

Figure 2. (A). Diabetic treated liver showing enlargement of many hepatocytes with dark stain nuclei and most hepatocyte with devoid from cytoplasm content. Notice: some cells devoid of nuclei (arrows) (H\&E, X400).

(B). Diabetic treated liver: Marked necrosis in some areas of hepatocytes (arrows) (H\&E, X100). (C). Diabetic liver showing hepatocytes were hypertrophic due to an increase in intracytoplasmic metachromatic granules $(\uparrow)$. Other cells were devoid from cytoplasmic contents with homogeneous toluidine blue stain inclusions $(\uparrow \uparrow)$ (Toluidine blue, X1000). (D). Diabetic liver showing hepatocytic metachromatic granules $(\uparrow)$ and the nuclei of binuclear hepatocytes were not identical in staining and varied in size one of both was pyknotic ( $\uparrow)$ (Toluidine blue, X1000). (E). Diabetic liver ultrastructure showing binuclear hepatocytes were not identical in size, one of both appeared pyknotic $(\uparrow \uparrow)$ and markedly reduced clumped cytoplasmic organelles around the nucleus leaving rarified areas in the cytoplasm (R) (X2900). (F). D+ASP liver: Degeneration of many cells and most of the cells lost their cell boundaries (H\&E, X400).

areas with negative PAS reaction due to marked necrosis of hepatocytes in large area (Figure 4B). Group (3) rats which received STZ showed a negative reaction in large area of hepatocytes while others showed a moderate amount of polysaccharides (Figure 4C).

In D+ASP group, PAS reaction showed depletion of carbohydrate content in many hepatocytes and few cells with a moderate amount of carbohydrate content compared to 

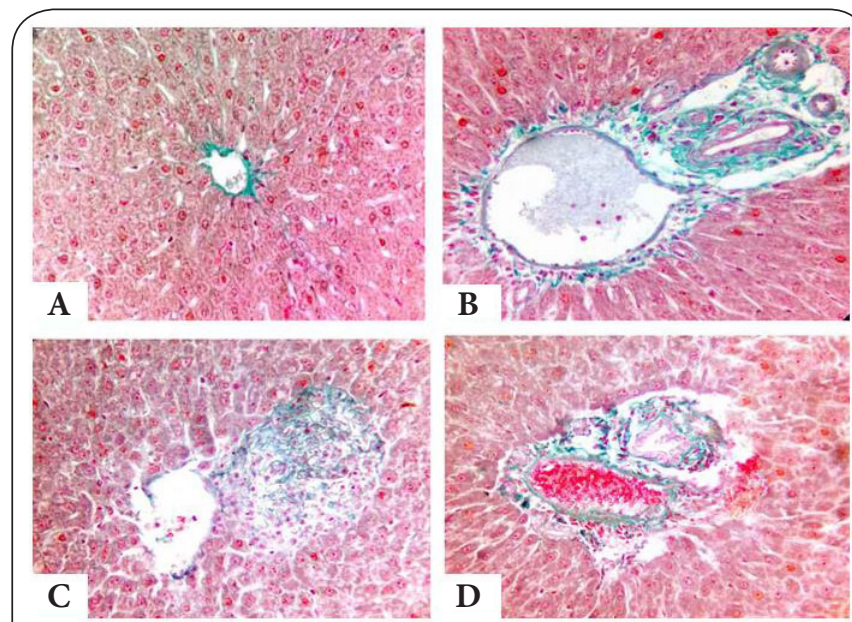

Figure 3. (A). Normal liver section showing normal distribution of small amount of collagenous fibers around the central vein. (B). ASP liver section: A large amount of collagenous fibers around portal area. (C). Diabetic liver showing foci of a large amount of collagenous fibers between hepatocytes. (D). D+ASP liver: Increase amount of collagenous fibers around congested blood vessel and bile ducts. (Masson's trichrom stain, X400).

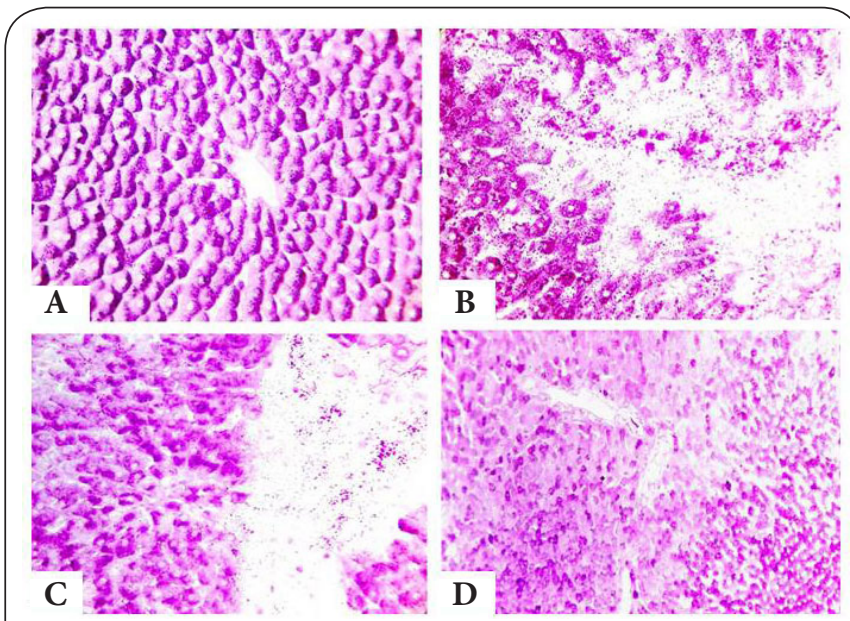

Figure 4. (A). Liver section showing normal considerable amount of polysaccharide granules in the ground cytoplasm of hepatocytes and a pale rounded areas within the cells which represent the nuclei (PAS reaction, X400). (B). ASP treated liver: Large area with negative PAS reaction due to marked necrosis of hepatocytes in some areas. Other hepatocytes with considerable amount of carbohydrate content PAS reaction, $\mathrm{X} 400)$. (C). Diabetic liver showing negative reaction in large area of hepatocytes (PAS reaction, X 400). (D). D+ASP rat liver: High depletion of carbohydrates content in most of hepatocytes and other cells with +ve PAS reaction (PAS reaction, $\mathrm{X} 100)$.

the control group (Figure 4D). This depletion was decrease compared to the previous treated group.

Electron microscope examination revealed that, the control hepatocytes contain a rather centrally located rounded or oval nucleus with normal distribution of hetero- and euchromatin. The liver cells contain a well developed rough endoplasmic reticulum, which is arranged in parallel stacks. Their outer surfaces are studded with ribosomes. The mitochondria were avoided or elongated in shape and scattered throughout the cytoplasm (Figure 5A).

Investigation of electron microscopy revealed marked changes in the treated animal of the three treated groups compared to the control group. After ASP administration, (group 2) hepatocytes showed presence of phagosome, and small amounts of collagenous fibers between hepatocytes were observed indented (Figure 5B). Some cells appeared with

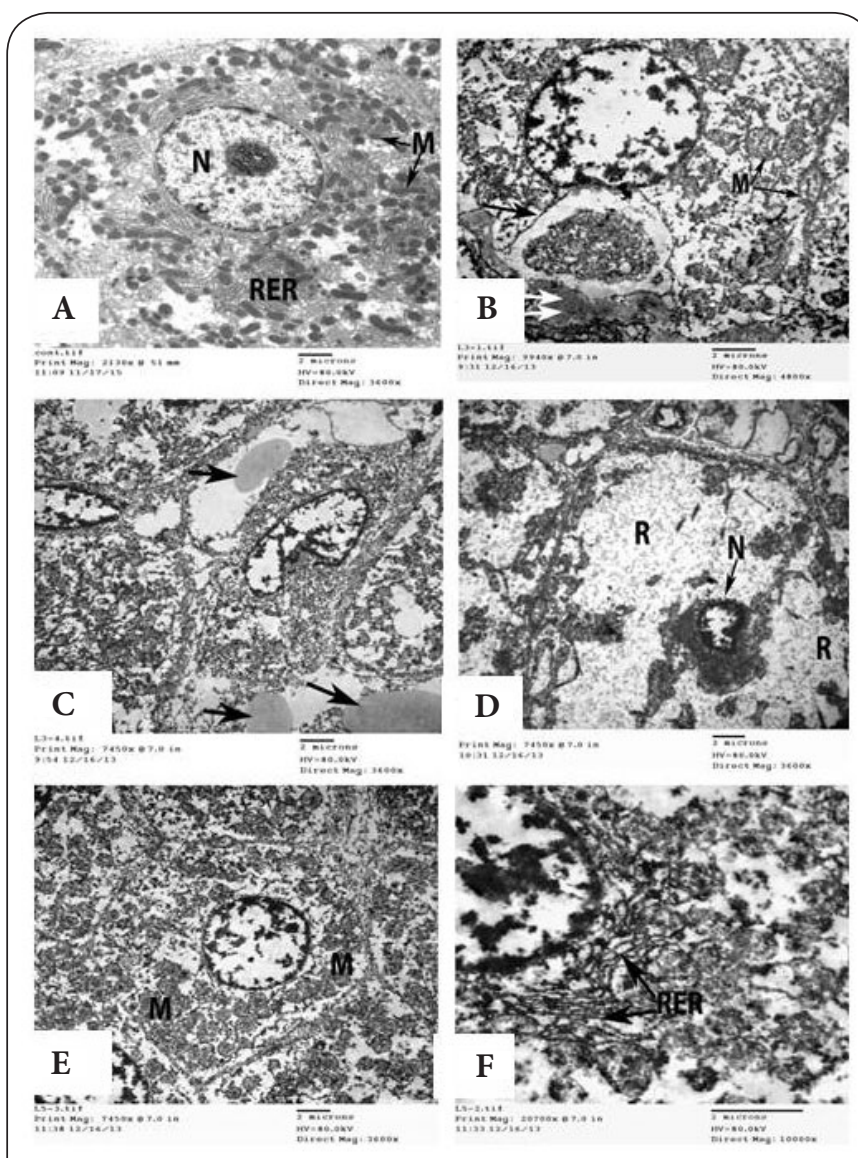

Figure 5. Ultrastructure (A). Control rat showing; centrally located rounded nuclei $(\mathrm{N})$, normal distribution of hetero and euchromatin and well-developed RER and mitochondria with dense matrices and vary in shape (X3600). (B). ASP treated liver showing large phagosome $(\uparrow)$, collagen fiber between hepatocytes $(\uparrow \uparrow)$ and destruction of mitochondria cristae (M) (X4800). (C). ASP treated liver: Large lipid droplets (arrows) and deeply indentation of the nucleus with peripheral condensed chromatin (X3600). (D). Diabetic liver showing clumps of cytoplasmic organelles around the nucleus $(\mathrm{N})$ leaving large rarified area in the cytoplasm (R) (X3600). (E) -D+ASP rat liver: Increase of number of mitochondria (M) (X3600) and well develop rough endoplasmic reticulum (RER) $(\mathrm{X} 10000)(\mathbf{F})$. 
Khidr et al. Journal of Histology \& Histopathology 2017,

irregular nuclei and clumps of condensed heterochromatin (Figure 5C). Also, other hepatocytes showed fatty changes indicated by the presence of large lipid droplets in the cytoplasm (Figure $\mathbf{5 C}$ ).

In diabetic animals (group 3), there were more marked changes than those seen in previous treated group. In severely affected hepatocytes, the nuclei appeared degenerated and very small (pyknosis). In other nuclei, the hetero chromatin clumps and appears dark (Figure 5D). The cytoplasm is highly vacuolated resulting in disorganization and dissociation of cellular organelles (Figure 5D).

In group 4 ( $D+A S P)$, the electron microscope examination showed decrease in the changes compared to the two previous treated group. However, an increase in mitochondria and rough endoplasmic reticulum were observed (Figures 5E and 5F). Vacuolation of cytoplasm is less than those in the two previous treated groups (Figure 5F).

\section{Discussion}

ASP is one of the most widely used of sweeteners in the world [4]. ASP is used frequently nowadays to reduce sugar consumption and to decrease caloric intake in healthy person as well as in diabetic patients [7]. This sweetener ASP possesses 180-200 times the sweetness potency of sucrose and has a caloric value of $4 / \mathrm{kcal} / \mathrm{g}$ [9]. Diabetes is a chronic disease that is relatively common throughout the world. It is a complex metabolic disorder resulting from either insulin insufficiency or insulin deficiency dysfunction [11].

The liver is a chief metabolic organ responsible for disposal of up to one third of an oral glucose load and involved in the regulation of glucose metabolism [15]. In the present study, in the aspartame treated groups of male albino rats both light and electromicroscopic investigations displayed obvious histopathological and ultrastructural changes. These changes are in the form of disarrangement in paranchymal cells, vacuolation of cytoplasm, and disorganization of cellular organelles. Moreover, the glycogen granules were decreased while the amounts of collagenous fibers were increased in the portal area. In this respect, pathological changes in male albino rats resemble those in female albino rats in other studies [22]. On the contrary, no obvious changes in the liver treated with aspartame were described by other investigation [23], who stated that aspartame was found to be rapidly metabolized with negligible toxicity and border line liver decomposition.

In the present investigation, the hepatocytes showed cytoplasmic vacuoles after aspartame ingestion. Cytoplasmic vacuolation formation may be as a defense mechanism against toxic agents entering the cell. Either these toxic substances aggregated in the vacuoles interfering with cellular metabolism [24] or these toxic substances cause disarrangement of cytoskeletal components leading to cytoplasmic vacuolation [25]. Furthermore, other study [26] suggested that the physical changes in the structure of plasma membranes of protein and lipids of different organelles might be resulted from cytoplasmic vacuoles in hepatocytes. Production of methanol and aspartic acid which leads to the release of free radicals was due to the Ingestion of ASP. Free radicals affect $\mathrm{Na} / \mathrm{K}$ pump function leading to $\mathrm{Na}$ accumulation and water migration to the cells [26]. Moreover, methanol could increase lipid peroxidation which increase the surface charge density and act as an auto catalytic mechanism leading to oxidative destruction of cellular membrane as noted by other reports $[27,28]$.

In the present investigation, a decrease in the amount of mitochondria and along with deformation of their cristae was observed in diabetic rats. Similar results were reported by Guven et al., [29]. However, in other studies, an increase in the amount of mitochondria was observed in the hepatocytes of the liver tissue in diabetic mice $[30,31]$ and in diabetic rat [32]. Remedio et al., [33] reported that the increased amount of mitochondria may have an important meaning in diabetes development, indicating a high rate of cellular respiration and, thus, higher demand for ATP by the cell. This suggests the occurrences of numerous chemical reactions in these mice, at higher intensity than in controls. These reactions may be represented by the transformation of glycogen into glucose, or even the production of glucose through gluconeogenesis. Nukatsuka et al., [34] suggested that STZ inhibited mitochondrial ATP generation in vitro, and it is reasonable to consider that in vivo a similar phenomenon will also occur. In addition Kume et al., [31] found that a marked increase in number of mitochondria in hepatocytes in STZ-induced diabetic mice may be related to the depression of energy production in individual mitochondrion. In diabetic rat, Welt et al., [35] reported swelling mitochondria by about $28 \%$, which may be considered as compensation of impaired mitochondrial ATP production and membranes damaged by hydroxyl radicals [36]. Furthermore Lefkowitch et al., [37] also observed high increase in number of mitochondria in hepatocytes in chronic active hepatitis and they regarded it as a compensatory response to a decreased energy supply to hepatocytes.

In the present investigation, a degeneration and reduction in the amount of RER of hepatocytes was observed in STZ induced diabetic rats. Similar results were reported in many studies [33,38,39]. In STZ-treated animals, Lenk et al., [39] found that organelle degeneration and hepatocyte vacuolization were prevented by insulin administration. Their results indicating that these effects were caused by insulin deficiency and not by STZ toxicity. According to Laguens et al., [40] and Kume et al., [31], the reduction in RER resulted from diabetes induction may be due to the restricted synthesis capacity of the liver, and has been described as degranulation and fragmentation of its membranes.

The present study showed increased collagen fiber deposition around the portal area and in between the hepatocyte in D+ASP rats. Similar conditions were reported by other studies [22,33,41]. On the other hand, Guven et al., [29] did not observe marked peri-sinusoidal fibrosis or increase in 
collagen fibers in the diabetic liver. These results were most probably due to the effect of the metabolites of aspartame on the cell proteins [22]. This opinion is in agreement with our study which observed a significant elevation in lipid peroxidase level in the liver tissue of rats after 28 days treatment with aspartame. A similar result was reported by [28]. Lipid peroxidation induce oxidative damage to proteins and nucleic acids which lead to increased collagen and ground substance formation [42]. However, many authors have suggested that the fibrosis detected in diabetic liver is not directly related to diabetes, but is due to an underlying genetic tendency rather than hyperglycemia itself and a liver vascular abnormality in the rat's strain $[43,44]$.

A decreased carbohydrate content was detected in the liver of STZ-induced diabetic rats was previously reported in animal models of diabetes $[27,31,35,45]$.

The reduction of glycogen content in diabetics can be explained by the decrease of glycogen synthase activity $[46,47]$ and/or increase of glycose-6-phosphate activity [48]. In addition, the break-down of glycogen in diabetics, would increase hypoglycemia and induce more damage to the liver and whole body [33]. Also, the current study showed decreased glycogen in the liver of the group administered aspartame. The present results are in agreement with many previous studies $[49,50]$. Also, Kumar et al., [51] mentioned that the glycogenolytic effect of additive may be due to its direct action on the stimulating glycogenolysis. The present results are in correlation with our previous and recent work which revealed changes in liver functions and increase the oxidative stress marker after ASP administration to normal and diabetic rats [52].

\section{Conclusion}

Our study revealed that ASP induced morphological changes in the hepatocytes of both normal and diabetic rats. Also, our results recommend that the use or administration of ASP must be in accordance of the universal doses.

\section{Competing interests}

The authors declare that they have no competing interests.

Authors' contributions

\begin{tabular}{|l|c|c|c|}
\hline Authors' contributions & BMK & GHE & SMS \\
\hline Research concept and design & $\checkmark$ & $\checkmark$ & $\checkmark$ \\
\hline Collection and/or assembly of data & $\checkmark$ & $\checkmark$ & $\checkmark$ \\
\hline Data analysis and interpretation & $\checkmark$ & $\checkmark$ & $\checkmark$ \\
\hline Writing the article & $\checkmark$ & $\checkmark$ & $\checkmark$ \\
\hline Critical revision of the article & $\checkmark$ & $\checkmark$ & $\checkmark$ \\
\hline Final approval of article & $\checkmark$ & $\checkmark$ & $\checkmark$ \\
\hline Statistical analysis & -- & -- & -- \\
\hline
\end{tabular}

Publication history

EIC: Gaetano Giuseppe Magro, University of Catania, Italy. Received: 01-Nov-2016 Final Revised: 09-Dec-2016 Accepted: 02-Jan-2017 Published: 13-Jan-2017

\section{References}

1. Duyff R. L. American Dietetic Association complete food and Nutrition Guide. 2ed ed., John Wiley \& Sons, Inc. 2002; 127:194-198. I Article

2. Wardlaw G. M. Carbohydrates in foods. In: "Contemporary Nutrition Tssues and Insights". 4th ed., MC Graw Hill, Boston, New York, San Francisco. 2000; 117-120. | Book

3. Marion J and Franz M.S. Use of nutritive and non-nutritive sweetener. J. Am. Diet. Assoc. 1993; 93:816-821.

4. Hazardous Substances Data Bank. TOXNET: Toxicological Data Network. 2005. I Website

5. Mazur R. The discovery of aspartame. In aspartame: physiology and Biochemistry (stegink, L.D. and Filer, L.J., Jr., eds), Marcel Dekker New York, Chap. 1984.

6. Wardlaw G. M and Kessel M.W. Carbohydrates. In: "Perspectives in Nutrition". 5th edition. MC Graw Hill, Boston, New York, London, 2002; 189. | Book

7. Meyer H. Aspartame as part of the solution. Food Sci. Technol. 2005; 19:43-45.

8. Humphries $P$, Pretorius $E$ and Naude $H$. Direct and indirect cellular effects of aspartame on the brain. Eur J Clin Nutr. 2008; 62:451-62. | Article I PubMed

9. American dietetic association (ADA). Use of nutritive and non-nutritive Sweeteners. Journal of the American Dietetic Association. 1998; 98:580.

10. Weihrauch MR and Diehl V. Artificial sweeteners--do they bear a carcinogenic risk? Ann Oncol. 2004; 15:1460-5. | Article I PubMed

11. Kasper D.L, Braunwald E, Fauci A.S, Hauser S.L, Longo D.L and Jamesan J.L. Harrison Principles of internal Medicine 16th Edn Newyork Mc Graw Hill. 2005; 2:2152-79. | Book

12. Szkudelski T, Kandulska K and Okulicz M. Alloxan in vivo does not only exert deleterious effects on pancreatic B cells. Physiol Res. 1998; 47:3436. | Pdf $\mid$ PubMed

13. Junod A, Lambert AE, Orci L, Pictet R, Gonet AE and Renold AE. Studies of the diabetogenic action of streptozotocin. Proc Soc Exp Biol Med. 1967; 126:201-5. I PubMed

14. Masiello P, Karunanayake EH, Bergamini E, Hearse DJ and Mellows G. (14C) Streptozotocin: its distribution and interaction with nucleic acids and proteins. Biochem Pharmacol. 1981; 30:1907-13. | Article | PubMed

15. Michael MD, Kulkarni RN, Postic C, Previs SF, Shulman GI, Magnuson MA and Kahn CR. Loss of insulin signaling in hepatocytes leads to severe insulin resistance and progressive hepatic dysfunction. Mol Cell. 2000; 6:87-97. | Article | PubMed

16. Rakieten N, Rakieten ML and Nadkarni MV. Studies on the diabetogenic action of streptozotocin (NSC-37917). Cancer Chemother Rep. 1963; 29:91-8. | Article | PubMed

17. Drury R.V.A and Walligton E.A. Carltons histological techniques, 5th ed. Oxford University Press, New York, Pronto. 1980; 206. I Website

18. Gupta P.D. Ultrastructural study on semithin section. Sci. Tools. 1983; 30:6-7. | Website

19. Mourad I.M. Effect of aspartame on some oxidative stress parameters in liver and kidney of rats. Afr. J. Pham Pharmacol. 2011; 5:678-682. | Article

20. Eileen Dolan M. Inhibition of DNA repair as a means of increasing the antitumor activity of DNA reactive agents. Adv Drug Deliv Rev. 1997; 26:105-118. | Article | PubMed

21. Szkudelski T. The mechanism of alloxan and streptozotocin action in B cells of the rat pancreas. Physiol Res. 2001; 50:537-46. I Pdf I PubMed

22. Abd Elfatah AA, Ghaly IS and Hanafy SM. Cytotoxic effect of aspartame (diet sweet) on the histological and genetic structures of female albino rats and their offspring. Pak J Biol Sci. 2012; 15:904-18. | Article | PubMed

23. Hertelendy ZI, Mendenhall CL, Rouster SD, Marshall L and Weesner R. Biochemical and clinical effects of aspartame in patients with chronic, stable alcoholic liver disease. Am J Gastroenterol. 1993; 88:737-43. | 
Khidr et al. Journal of Histology \& Histopathology 2017,

Article | PubMed

24. Robbins S.L, Cotran R.S and Kumar V. Pathologic basis of disease. 3rd ed. Philadelphiag PA: W.B. Saunders. 1984. | Book

25. Tanemura $K$, Kurohmaru $M$, Kuramoto $K$, Matsumoto $M$ and Hayashi $Y$. Age-related changes in cytoskeletal components of the BDF1 mouse Sertoli cell. Tissue Cell. 1994; 26:447-55. | Article I PubMed

26. Butchko H.H, Stargel W.W, Comer C.P, Mayhew D.A, Benninger C, Black burn G.L, de Sonneville L.M, Geha R.S, Hertelendy Z, Koestner A.L and Leon A.S. et al. Aspartame: review of safty. Regul. Toxicol. Pharmacol. 2002; 35:S1-S93. | PubMed

27. Dobrzynska I, Skrzydlewska E, Kasacka I and Figaszewski Z. Protective effect of $\mathrm{N}$-acetylcysteine on rat liver cell membrane during methanol intoxication. J Pharm Pharmacol. 2000; 52:547-52. | Article | PubMed

28. Iman M.M. Effect of aspartame on some oxidative stress parameters in liver and kidney of rats. Afr. Journal of Pharmacy and Pharmacology. 2011; 5:678-682. | Pdf

29. Guven A, Yavuz O, Cam M, Ercan F, Bukan N Comunoglu C and Gokce F. Effect of melatonin on streptozotocin-induced diabetic liver injury in rats. Acta. Histochem. 2006; 108:85-93. I Article

30. Doi K, Yamanouchi J, Kume E and Yasoshima A. Morphologic changes in hepatocyte nuclei of streptozotocin (SZ)-induced diabetic mice. Exp Toxicol Pathol. 1997; 49:295-9. | Article | PubMed

31. Kume E, Ohmachi Y, Itagaki S, Tamura K and Doi K. Hepatic changes of mice in the subacute phase of streptozotocin (SZ)-induced diabetes. Exp Toxicol Pathol. 1994; 46:368-74. | Article | PubMed

32. Cam MC, Brownsey RW and McNeill JH. Mechanisms of vanadium action: insulin-mimetic or insulin-enhancing agent? Can J Physiol Pharmacol. 2000; 78:829-47. | Article | PubMed

33. Remedio R.N, Barbosa R.A, Castellar A, Gomes R.J and Caetano F.H. Histochemical and ultra-structural analysis of hepatic glycogen and collagen fibers in alloxan-induced diabetic rats submitted to long-term physical training tissue and cell. 2011; 43:207-215. | Article | PubMed

34. Nukatsuka M, Yoshimura $Y$, Nishida $M$ and Kawada J. Importance of the concentration of ATP in rat pancreatic beta cells in the mechanism of streptozotocin-induced cytotoxicity. J Endocrinol. 1990; 127:161-5. | Article | PubMed

35. Welt K, Weiss J, Martin R, Dettmer D, Hermsdorf T, Asayama K, Meister $S$ and Fitzl G. Ultrastructural, immunohistochemical and biochemical investigations of the rat liver exposed to experimental diabetes und acute hypoxia with and without application of Ginkgo extract. Exp Toxicol Pathol. 2004; 55:331-45. | Article | PubMed

36. Ohkuwa T, Sato $\mathrm{K}$ and Naoi M. Hydrozyl radical formation in diabetic rat induced by streptozotocin. Life sciences. 1995; 56:1789-1798. | Article | PubMed

37. Lefkowitch JH, Arborgh BA and Scheuer PJ. Oxyphilic granular hepatocytes. Mitochondrion-rich liver cells in hepatic disease. Am J Clin Pathol. 1980; 74:432-41. | Article | PubMed

38. Bahnak BR and Gold AH. Effects of alloxan diabetes on the turnover of rat liver glycogen synthase. Comparison with liver phosphorylase. J Biol Chem. 1982; 257:8775-80. | Article | PubMed

39. Lenk SE, Bhat D, Blakeney W and Dunn WA, Jr. Effects of streptozotocininduced diabetes on rough endoplasmic reticulum and lysosomes of rat liver. Am J Physiol. 1992; 263:E856-62. | Article | PubMed

40. Laguens RP, Candela S, Hernandez RE and Gagliardino JJ. Streptozotocininduced liver damage in mice. Horm Metab Res. 1980; 12:197-201. | Article | PubMed

41. Balazs $M$ and Halmos T. Electron microscopic study of liver fibrosis associated with diabetes mellitus. Exp Pathol. 1985; 27:153-62. | Article I PubMed

42. Bacon BR and Britton RS. Hepatic injury in chronic iron overload. Role of lipid peroxidation. Chem Biol Interact. 1989; 70:183-226. | Article | PubMed

43. Bernuau D, Guillot R, Durand AM, Raoux N, Gabreau T, Passa P and Feldmann $G$. Ultrastructural aspects of the liver perisinusoidal space in diabetic patients with and without microangiopathy. Diabetes. 1982; 31:1061-7. | Article | PubMed
44. Latry P, Bioulac-Sage P, Echinard E, Gin H, Boussarie L, Grimaud JA and Balabaud $C$. Perisinusoidal fibrosis and basement membrane-like material in the livers of diabetic patients. Hum Pathol. 1987; 18:775-80. | Article | PubMed

45. Whitton PD and Hems DA. Glycogen synthesis in the perfused liver of streptozotocin-diabetic rats. Biochem J. 1975; 150:153-65. | Article | PubMed Abstract | PubMed FullText

46. Hornbrook KR. Synthesis of liver glycogen in starved alloxan diabetic rats. Diabetes. 1970; 19:916-23. | Article | PubMed

47. van de Werve $G$, Proietto J and Jeanrenaud B. Control of glycogen phosphorylase interconversion by phorbol esters, diacylglycerols, $\mathrm{Ca2+}$ and hormones in isolated rat hepatocytes. Biochem J. 1985; 231:511-6. | PubMed Abstract | PubMed FullText

48. Lavoie $L$ and van de Werve $G$. Hormone-stimulated glucose production from glycogen in hepatocytes from streptozotocin diabetic rats. Metabolism. 1991; 40:1031-6. | PubMed

49. Hamoudah S.Y.M. Toxicological effects of some food additives. M.Sc. Thesis, Al-Azhar University, Cairo, Egypt. 1990; 109-112.

50. Sadek I.M. and Abd El-Maksoud. Biological and histological studies on the effect of aspartame and alitame in normal rats Egypt. J. Anat. 1997; 20:121-146.

51. Kumar V, Abbas A.K and Fausto N. Robbens and Catron Pathologic (Basis of Disease 7th ed Elsevier Saunders). 2005; 6-17.

52. El-Sokkary G.H, Khidr B.M and Saleh Sh.M. M. Aspartame-induced oxidative stress on liver and kidney in normal and diabetic adult male rat. IJAR. 2016; 6: 511-513.

\section{Citation:}

Khidr BM, El-Sokkary GH and Saleh SMM. Study on morphological changes induced by aspartame on liver of normal and diabetic male albino rats.

J Histol Histopathol. 2017; 4:1.

http://dx.doi.org/10.7243/2055-091X-4-1 